\title{
Revus
}

Journal for Constitutional Theory and Philosophy of Law / Revija za ustavno teorijo in filozofijo prava

42 | 2020

Internal legal positivism

Symposium on the internal legal positivism

\section{Positivismo jurídico "interno" a la luz del derecho natural}

\section{Imágenes y objeciones del derecho natural en la filosofía jurídica analítica contemporánea}

"Internal" legal positivism in the light of natural law. Images and objections of natural law in contemporary analytical jurisprudence

SANTIAGO LEGARRE

https://doi.org/10.4000/revus.6128

\begin{abstract}
s
Español English

Este trabajo se centra, de un modo crítico, en el uso de la palabra "iusnaturalismo" que hace Cristina Redondo en su libro Positivismo jurídico "interno", prestando especial atención a la relevancia práctica de dicho uso. Se hace notar cómo el análisis del iusnaturalismo de Redondo, en términos de "reducción" de normas jurídicas a normas morales, no hace honor al iusnaturalismo, pues omite una distinción importante entre dos modos de derivación de la ley positiva a partir de la ley natural. Por otro lado, se muestra cómo el análisis de Redondo no parece contemplar la realidad de que para el iusnaturalismo hay distintos grados de validez, lo que permite llamar "derecho" al derecho injusto. Finalmente, se busca mostrar puntos de armonía y de posible compatibilidad entre la teoría de Redondo y el iusnaturalismo.

This article focuses on the use of the term and concept "natural law theory" in Cristina Redondo's book Positivismo jurídico "interno". The article notes that Redondo's analysis of natural law theory is lacking in that the idea it ascribes to this theory of reducing legal norms to moral norms does not exist in the true "natural law theory". For this theory there are two ways of deriving positive law from natural law, which Redondo does not take into account. Moreover, her understanding misses the reality that according to natural law theory unjust laws are laws. Finally, this article tries to show possible ways how Redondo's theory can be compatible with natural law theory.
\end{abstract}


Keywords: natural law; legal positivism; Redondo (Cristina); Aquinas (Thomas); Finnis (John)

Palabras claves: ley natural; positivismo jurídico; Redondo (Cristina); de Aquino (Tomás); Finnis

(John)

\section{Full text}

\section{Introducción}

Este ensayo gira en torno de algunos conceptos contenidos en el libro de Cristina Redondo Positivismo jurídico "interno". Más concretamente, mis observaciones se centrarán en el uso de la palabra "iusnaturalismo" que la autora hace en su primer capítulo, titulado "Sobre la existencia y el conocimiento de normas",1 como también en la relevancia práctica que de ese uso se sigue para su discurso argumental. Digo esto último de la relevancia práctica, pues no se tratará aquí solamente de observar y, como se verá, de objetar el uso que la autora hace de una palabra. Si solo de ello se tratara, mis propias observaciones y objeciones serían pasibles de una razonable crítica nominalista: De nominibus non est disputandum.2 Es decir, ¿qué más da que ella llame así lo que yo (y otros) llamamos de manera distinta? Solamente importa un nombre distinto cuando la distinta nomenclatura arrastra o conlleva un error conceptual. En este último caso, si hubiera una diferencia entre nosotros, no sería meramente terminológica sino, además y más importante, se trataría de una diferencia de conceptos y, consiguientemente, de realidades.

Ya antes del primer capítulo, en el prefacio, la autora anuncia que su teoría positivista "normativista" o "interna" intentará "confutar un enfoque anti-positivista, ya sea de carácter iusnaturalista o interpretativista".3 A su vez, el positivismo de Redondo contestará también "una visión [positivista] puramente empirista como es aquella defendida por el positivismo escéptico".4 Aunque dado el enfoque iusnaturalista de este comentario la afirmación precedente de Redondo no es relevante para sus fines (del comentario), cabe destacar que dicha afirmación seguramente colocaría a la autora del mismo lado en que se encuentra el verdadero iusnaturalismo, el cual también es crítico de toda forma de escepticismo.5 En efecto, el tipo de positivismo que defiende Redondo considera, en contra de la vertiente escéptica del positivismo, que es posible conocer los deberes jurídicos. Esto es un punto de acuerdo con el iusnaturalismo, pues la tesis de ella apoya la posibilidad del conocimiento y seguimiento de reglas, al igual que la filosofía jurídica del paladín del iusnaturalismo, Tomás de Aquino.6 Por cierto, Redondo, con terminología en boga, llama "cognitivismo" a esta posibilidad del conocimiento y seguimiento de reglas;7 y, aunque para la Real Academia Española la palabra "cognitivismo" no merezca la inclusión en su Diccionario, más de un iusnaturalista contemporáneo estaría seguramente feliz de compartir con Redondo su cognitivismo, e incluso su terminología (de ella). 8

3 Anoto al pasar, y aunque no retomaré aquí este punto, que leo la expresión del libro citada en el párrafo precedente ("ya sea de carácter iusnaturalista o interpretativista") como indicando que un enfoque anti-positivista puede ser o bien iusnaturalista o bien interpretativista. Es decir, que "iusnaturalista" e "interpretavista" no serían sinónimos sino alternativas y variantes de "antipositivismo".

\section{El uso del término "iusnaturalismo" en la obra de Redondo}

A modo de preámbulo, cabe decir que la obra de la profesora Redondo es ajena a la tradición iusnaturalista y en ningún momento pretende lo contrario.9 Por ello, sería mucho pedir -injusto pedir, por usar un adjetivo muy iusnaturalista, como se verá- que ella incluyera en este libro amplias referencias al tema que, por mi especialidad, constituye el principal enfoque de este trabajo. Dicho lo cual, y dado que se trata de una autora erudita, honesta, e inteligente, su obra se distingue por contener algunas referencias al "iusnaturalismo", a diferencia de la gran mayoría de las obras de su género que, lamentablemente, parecen ignorarlo por completo. 
Sin contar la aludida referencia del prefacio, el primer contexto en el que, dentro del primer capítulo, Redondo se refiere al iusnaturalismo es en su abordaje de las "proposiciones que expresan deberes", con las que dicho capítulo empieza. Redondo no define nunca "iusnaturalismo"; simplemente usa el término; dado lo cual conviene recordar su definición convencional (es decir, generalmente aceptada), según la cual "iusnaturalismo" (y su equivalente en otras lenguas, como en inglés, donde se lo llama "natural law theory"10) es la corriente iusfilosófica según la cual (i) existe una normatividad moral cognoscible, objetiva y preexistente a cualquier ordenación convencional o positiva;11 (ii) dicha normatividad moral, llamada generalmente "ley natural" o "ley moral natural"12 (y, por algunos, "derecho natural"), sirve como vara o medida de evaluación moral de toda ordenación convencional o positiva;13 y (iii) como tal vara o medida, la ley natural permite descalificar moralmente como injusta toda ordenación convencional o positiva contraria a ella (sin que ello importe de por sí abrir juicio sobre las exactas consecuencias de dicha descalificación en el plano jurídico).

Recordada la definición de iusnaturalismo, vuelvo a la obra de Redondo. Al tratar las "proposiciones que expresan deberes", ella empieza por reconocer que:

La idea según la cual enunciados como "En Italia es obligatorio conducir por la derecha" o "En Holanda está permitida la eutanasia" expresan proposiciones que hacen referencia a deberes jurídicos ha sido fuertemente rechazada (Redondo 2018: 14).

En primer lugar, sostiene, esa idea ha sido rechazada por el positivismo realista o nonormativista (que no es el suyo, al que llama, como vimos, "normativista" o "interno"14). A los argumentos de distinta orientación que enarbolan este rechazo los llama "reduccionistas y nodescriptivistas" (Redondo 2018: 15).

El primer ejemplo que elige de este reduccionismo realista o no-normativista es la posición de Riccardo Guastini sobre la validez y la existencia de las normas jurídicas - un argumento apoyado sobre la forma lógica de los enunciados-. Guastini ofrece, según Redondo, tres argumentos "en contra de la admisión de enunciados deónticos entendidos como formulaciones de proposiciones normativas" (Redondo 2018: 16), que aquí no vienen a cuento, más allá de su intrínseca pertinencia y de la que tienen en el discurso de la autora.15

En cambio, lo que me importa traer a colación es lo que Redondo escribe al tratar el segundo argumento, pues aquí entra en escena el "iusnaturalismo". Ella aclara entonces que, dentro de este segundo argumento, para que se produzca la "reducción" anunciada por Guastini, la existencia de un enunciado normativo (por ejemplo, la norma "la eutanasia está permitida” es válida sí y solo sí la eutanasia está permitida) debe entenderse en un sentido empírico. Y agrega:
Por ejemplo, si pensamos en términos iusnaturalistas, la equivalencia conduce a una conclusión muy diferente. En este último caso, la existencia de una norma se analiza en términos de la existencia del deber o la permisión moral que ella establece. Es decir, la norma 'Prohibido robar' es válida (existe) si y sólo si moralmente no se debe robar, y esta equivalencia nos conduce a afirmar que una norma es válida solamente cuando es verdadera la proposición normativa que hace referencia a un hecho moral (el deber o la permisión de hacer u omitir algo) (Redondo 2018: 19, énfasis agregado; cita de von Wright omitida).

La verdad es que, en mi opinión, si este párrafo sobre el iusnaturalismo no estuviera en sus páginas, nada le cambiaría al libro y a su argumento central, que se mueven por otros derroteros. Pero, dado que el párrafo está, me abocaré a analizarlo para verificar si constituye una adecuada caracterización de los aludidos "términos iusnaturalistas", a la luz de la ya ofrecida definición convencional del iusnaturalismo.

Como surge incipientemente de lo explicado más arriba, el iusnaturalismo no postula que para ser jurídicamente válida una norma deba ser también moralmente válida. Según el iusnaturalismo, existen dos tipos de derecho: el justo (que representa su caso central "analogado" principal16) y el injusto (que representa una versión defectuosa o aguada17 del caso central: un "analogado" secundario o derivado18). Ambos son derecho, pero con una gradación diversa, de manera semejante -salvando las evidentes diferencias- a lo que hace que un vaso de coca-cola y un vaso de coca-cola aguada sean ambos coca-cola, aunque con distinta gradación.19 Otro tanto cabe decir de la validez jurídica, a tal punto que Finnis usa la expresión versión "aguada" para referirse al caso secundario o derivado (de la ley injusta).20 Por esta razón, así como alguien puede confundir la coca-cola aguada con la verdadera coca-cola, también puede tenerse por jurídicamente válida una 
norma moralmente inválida (aun cuando desde el punto de vista moral pueda predicarse, simultáneamente, defecto (moral) de dicha validez jurídica). Por insistir una vez más con la metáfora, así como la coca-cola aguada tiene algo (o incluso bastante) de la coca-cola pura, también el derecho injusto tiene (más o menos, según el caso) elementos del derecho justo. Son estos elementos de justicia subsistentes en el derecho injusto los que justifican, precisamente, seguir llamándolo derecho (injusto), de un modo parecido a como el persistente sabor a coca-cola justifica llamar así a la coca-cola aguada.

Respecto del derecho justo -el que se "deriva" de la ley (moral) natural: se remonta a él-, el iusnaturalismo afirma que en aquel los principios morales habitan con dos intensidades distintas. Algunas normas jurídicas (y algunos aspectos de algunas normas jurídicas) constituyen, en palabras del iusnaturalismo clásico, "derivaciones por modo de conclusión”,21 a partir de la ley natural: lo que, con imperfección, podría describirse como lo hace Redondo, cuando alude a normas jurídicas que se "reducen" a normas morales. Así, la norma jurídica de su ejemplo, "prohibido robar", se reduciría a una norma moral, "prohibido robar", que realmente existe, según el iusnaturalismo. Digo que podría describirse así "con imperfección” porque en rigor la norma jurídica en materia de robo va a ser, y debe ser, más compleja que la norma moral en materia de robo. Por un lado, la norma jurídica determinará numerosos aspectos contingentes que requieren una regulación compatible con varias soluciones moralmente aceptables. Por otro, agregará un tipo de sanción que estará ausente en la equivalente norma moral en cuestión. Estas determinaciones (tanto de esos numerosos aspectos contingentes como de las sanciones) son denominadas por el iusnaturalismo clásico "derivación por modo de determinación"22 y nunca podrían "reducirse" a normas morales.23 Más bien, la norma jurídica que las establece, cuando es justa, parte de una norma moral mucho más general e indeterminada para concretar una nueva razón para la acción, antes inexistente. Así, si la norma moral en cuestión -que será, por definición, parte de lo que el iusnaturalismo clásico llama "la ley moral natural" - exige la justificación (moral) de algunos supuestos de robo, una norma jurídica justa determinará cuánto pan están jurídicamente autorizadas a tomar por la fuerza, para satisfacer su hambre, personas como Jean Valjean. La respuesta a esta precisa pregunta no está "escrita en las estrellas" (de la ley moral natural), como tampoco la pena que debería satisfacer el protagonista de Los miserables si por hambre se roba una panadería entera. Más bien, estará escrito en la letra de... la ley positiva.

De regreso al ejemplo de Redondo, y citándola a ella en parte, y parafraseándola en parte, para el iusnaturalismo "la norma 'Prohibido robar' es válida (existe)" si existe una norma jurídica que establezca "Prohibido robar".24 Y si es cierto que "moralmente no se debe robar," de esta verdad moral -i.e., de la existencia de esta norma moral- no se sigue que esté jurídicamente prohibido robar. Para que ello sea así, según el iusnaturalismo, debe promulgarse la correspondiente norma jurídica o, dicho con otras palabras más hartianas, una fuente social debe reconocer la norma moral sobre robo y dotarla de normatividad jurídica.

Para el iusnaturalismo, la prueba extrema de la diferencia entre validez moral y validez jurídica la brinda el tratamiento que dicha doctrina realiza de la ley injusta. Si, por ejemplo, estuviera jurídicamente prohibido donar dinero a los pobres, esta norma sería jurídicamente válida, si lo es, con independencia de que sea cierto moralmente que no debe donarse dinero a los pobres. La prohibición legal de donar dinero a los pobres podrá ser una prohibición injusta, pero no dejará de ser válida, de existir jurídicamente, por el hecho de ser injusta (o, lo que es igual, inmoral).25 A modo de recapitulación, si se habla de "derecho injusto" es porque... es "derecho".

\section{Conclusión: compatibilidad entre el iusnaturalismo y el positivismo normativista}

El segundo contexto en el que Redondo usa la expresión "iusnaturalismo" es semejante al anterior, por lo cual mis comentarios aquí serán una repetición y un desarrollo de lo sostenido en los párrafos precedentes.

Sostiene Redondo: 

agregado).

Sin embargo, se sigue de lo ya explicado que el iusnaturalismo no afirma que las normas jurídicas puedan "reducirse" a normas morales. Si bien, como vimos, para el iusnaturalismo el derecho justo se deriva de la ley moral natural (en el sentido de que se remonta a sus principios morales), esa teoría también admite la posibilidad de que una cierta norma jurídica, por su injusticia, no pueda remontarse a una norma moral. Más aún, en rigor para el iusnaturalismo muy pocas normas jurídicas, incluso justas, pueden "reducirse" a normas morales; algo parecido a "reducirse" podría decirse de aquellas normas jurídicas derivadas de la ley natural por modo de "conclusión”.26 Pero la mayoría de las normas jurídicas justas derivan de la ley natural por modo de "determinación”,27 donde lo que ocurre es que si bien la norma jurídica respeta la ley moral natural, la norma jurídica está lejos de reducirse a ella; más bien, toma un principio general moral y lo concreta en alguno entre muchos modos posibles, respecto de los cuales la ley moral natural es indiferente.

Lo que está detrás de este argumento es la idea iusnaturalista de la distinción entre moral y derecho como dos órdenes normativos relacionados pero distintos.28 $\mathrm{Si}$, en cambio, pudiera reducirse el derecho a la moral, el derecho no tendría razón de ser (o no tendría más razón de ser que aportar sanciones). Por el contrario, desde la perspectiva iusnaturalista la moral -la ley moral natural- es insuficiente para la vida en sociedad y por ello exige, ella misma, la existencia del derecho (mucho más allá de las sanciones, aunque incluidas estas). Si entiendo bien la posición de Redondo, en definitiva lo que habría entre ella y el iusnaturalismo, en este aspecto, es acuerdo. Y si ella no piensa lo mismo sugiero que a lo mejor sea porque lo que ella llama iusnaturalismo... no existe; o, al menos, no es el iusnaturalismo clásico (el de Tomás de Aquino, renovado por Finnis y otros).

El tercer contexto en el que Redondo usa la expresión "iusnaturalismo" refuerza la conclusión optimista a la que se acaba de llegar y permite ir un paso más lejos y aventurar una posible compatibilidad entre su posición y la doctrina de la ley natural. Este nuevo contexto no está incluido en el primer capítulo, sino más adelante; y en una nota al pie (la número 140). En el texto que corresponde a esa nota al pie sostiene Redondo que en Normative Systems:

no se pretende articular una específica "teoría del derecho", sino que se presenta una "teoría de los sistemas normativos" y se ofrece una variedad de herramientas que podrían ser utilizadas por muy diversas específicas teorías del derecho; naturalmente, siempre que ellas acepten la idea de que el derecho puede ser útilmente reconstruido como un sistema de normas (Redondo 2018: 139).

En nota al pie número 140 aclara que, al igual que José Juan Moreso, ella piensa que:

la noción de sistema normativo desarrollada en Normative Systems es una poderosa construcción conceptual aplicable a cualquier problema normativo... independiente de nuestra posición acerca de la naturaleza del derecho y compatible, por lo tanto, con el iusnaturalismo y con el iuspositivismo (Redondo 2018: 139, nota 140, con cita de Moreso; puntos suspensivos en el original).

21 Comparto también yo, al menos potencialmente, esta compatibilidad, en lo que al iusnaturalismo se refiere pues, por un lado, la doctrina de la ley natural es compatible con la predicación del concepto de derecho de sistemas normativos, donde estos existen (Rosler 2019). Por otro lado, dicha doctrina no se pronuncia acerca de los problemas lógicos y de otro tipo que se dan en los sistemas normativos (donde estos existen). Pero afirmar la potencial compatibilidad del iusnaturalismo con las soluciones propuestas en la famosa obra de Carlos Alchourrón y Eugenio Bulygin, no implica abrir juicio sobre la utilidad y la corrección de estas soluciones, asunto sobre el cual me declaro ignorantemente agnóstico; aunque, tal vez gracias al aprendizaje que significó para mí leerla a Cristina Redondo, si la lógica normativa fuera un dios y Normative Systems la biblia, de ninguna manera me proclamaría ateo, por las dudas.

Sin perjuicio de mi declarado agnosticismo, y a pesar de mi relativa ignorancia, advierto preliminarmente que las ideas de Normative Systems pueden ser útiles para comprender cómo es posible que un sistema jurídico contenga no solo las normas explícitamente establecidas en él sino también aquellas que son consecuencia lógica de las primeras. Noto, en este sentido, una analogía entre la tarea llevada a cabo por Alchourrón y Buygin en su "biblia" y la empresa de Tomás de Aquino en su "summa", sobre la derivación de normas dentro del plano de la moral, concluyendo en normas particulares a partir de otras más generales. Por ejemplo,29 sin salir de la órbita de la 
moral, Aquino concluía a partir del principio “deberás hacer el bien y evitar el mal”, en la existencia de un principio moral más concreto: "no deberás dañar al otro"; y de este, en la de otro más concreto aún: "no matarás".30 De la misma manera que el Aquinate aplicaba este método de derivación a la moral con respeto de la lógica aristotélica, los maestros analíticos argentinos hacían otro tanto (salvando las diferencias) en el plano jurídico: otra coincidencia que merece ser destacada y que, todo parece indicar, es también coincidencia entre la obra de Redondo y el iusnaturalismo.

-Agradecimientos. - Una versión previa de este trabajo ha sido presentada y discutida en una reunión académica organizada por la Asociación Argentina de Filosofía del Derecho, con la coordinación de Paula Gaido, en la Facultad de Derecho de la Universidad de Buenos Aires el 10 de septiembre de 2019. El autor agradece a Paula Gaido, Luciano Marchetti, Malena Muñoz y a dos referís de Revus sus valiosos comentarios y correcciones a una primera versión de este texto.

\section{Bibliography}

Alchourrón, C. E. \& Bulygin, E. (1971). Normative systems. Springer.

De Aquino, T. (1273). Summa Theologiae. Club de lectores.

Dworkin, R. M. (1986). Law's Empire. Fontana Press.

George, R. P. (1992): Natural Law Theory. Oxford University Press.

Finnis, J. M. (2011). Natural Law and Natural Rights (2a edición). Oxford University Press. (Original publicado en 1980).

Finnis, J. M. (1998). Aquinas: Moral, Political, and Legal Theory. Oxford University Press.

Finnis, J. M. (2000). Ley natural y derechos naturales. Abeledo-Perrot.

Finnis, J. M. (2012). Coexisting Normative Orders? Yes, but no. American Journal of Jurisprudence, 57, 111-117.

DOI : 10.1093/ajj/57.1.111

Hervada, J. (1981). Introducción crítica al derecho natural. EUNSA.

Hill, J. L. (2016). After the Natural Law. Ignatius Press.

Legarre, S. (1999). El concepto de derecho en John Finnis. Persona y Derecho, 40, 65-87.

Legarre, S. (2016). Reseña de Filosofía del Derecho, de Carlos I. Massini Correas. Persona y Derecho, $55,1067-1072$.

Legarre, S. (2012). Derivation of Positive from Natural Law Revisited. American Journal of Jurisprudence, 57, 103-110.

DOI : 10.1093/ajj/57.1.103

Legarre, S. (2013). La derivación del derecho positivo a partir de la ley natural y los principios jurídicos: un diálogo con John Finnis. Anuario de Filosofía Jurídica y Social, 32, 137-144.

Legarre, S. (2018). A new Natural Law Reading of the Constitution. Louisiana Law Review, 78, 877905.

Orrego, C. (2007). Natural law under other names: De Nomibus Non Est Disputandum. American Journal of Jurisprudence, 52, 77-92.

DOI : 10.1093/ajj/52.1.77

Redondo, C. (2018). Positivismo Jurídico "Interno". Klub Revus.

Rosler, A. (2019). La ley es la ley: Autoridad e Interpretación en la Filosofía del Derecho. Katz.

\section{Notes}

1 En verdad, y como se verá en la misma introducción de este ensayo, también se abordará aquí el uso que hace Redondo de la palabra "iusnaturalismo" en algún otro contexto más, además de en el primer capítulo del libro mencionado.

2 Sobre el significado y uso de este axioma latino, Orrego 2007: 77.

3 Redondo 2018: 9. Me gusta la palabra "interpretativista", elegida y usada por Redondo. Es preferible, desde el punto de vista estético, a la que puso de moda Dworkin en Law's Empire (Dworkin 1986: 46-47, por ejemplo): "interpretive" (de la cual deriva "interpretivist"; en español "interpretivista"). "Interpretive" e "interpretivist" no existen (o sea, no son mayormente usadas) en 
inglés (como tampoco en español existen "interpretivo" e "interpretivista”). Más bien la palabra adecuada, en inglés, sería "interpretative" (en español, "interpretativo"), de la cual deriva "interpretativist", cuya traducción al español es "interpretativista", el término acertadamente escogido por Redondo.

4 Redondo 2018: 9.

5 Finnis 1980/2011: 73-75.

6 De Aquino, Summa Theologiae, I-II, q 90 aa 1-4.

7 Redondo 2018: 13 y 21, por ejemplo.

8 Un ejemplo de "iusnaturalista contemporáneo", de los aludidos en el texto, es el argentino Carlos Ignacio Massini-Correas. En una reseña de uno de sus libros se señaló "el uso incansable por parte del autor de palabras extrañas, algunas de las cuales ni siquiera figuran en el diccionario de la Real Academia, como "axiótico", "contenutístico", y unas cuantas más [...] como "cognitivismo", "deóntico" y "metaética", entre otros". Legarre 2006: 1068, énfasis agregado.

9 En la reunión académica de septiembre de 2019, aludida en la introducción, la profesora Redondo reconoció sin rodeos, y con encomiable modestia, que, si bien su libro abordaba el asunto del iusnaturalismo, ella no tenía pretensiones ni expectativas de agotar el tema ni mucho menos.

10 George 1992: v.

11 Como acabo de señalar en el texto, Redondo, al igual que varios iusnaturalistas, llama "cognitivismo" a la posibilidad de conocer normas, con independencia de que estas sean (como lo es para el iusnaturalismo), objetivas y preexistentes a cualquier ordenación convencional o positiva. Véase, por ejemplo, Redondo 2018: 198, nota 202 (con referencia a Finnis, entre otros).

$12 \mathrm{El}$ adjetivo "moral", en "ley moral natural" busca distinguir la ley natural de las llamadas "leyes naturales". Véase Legarre 2018: 879-881, donde se contrasta la ley natural con lo que los clásicos llamaban la "ley eterna", que contiene las "leyes naturales" (de la física, la química, etc).

13 El término inglés "natural law" cubre, en la mayoría de los contextos, tanto el término castellano "ley natural" como su cognado "derecho natural". Hill 2016: 64-71. En cambio, en el contexto de los derechos subjetivos naturales, cuando el inglés usa la expresión "natural rights" (cada uno de los cuales es un "natural right"), el castellano usa "derechos naturales" (cada uno de los cuales es un "derecho natural"). Finnis 2000: 227-253.

14 Redondo 2018: 9.

15 A pesar de que, como acabo de explicar en el texto, la autora menciona tres argumentos en la página 16 de Positivismo jurídico "interno", yo solo pude encontrar el desarrollo de dos de los argumentos de Guastini en el libro de Redondo.

16 Hervada 1981: 131-133.

17 Como recuerda Finnis (1998: 443), el uso del agua en esta metáfora (“aguada") proviene originalmente del tratamiento que hace Aristóteles de la "analogía".

18 Finnis 2000: Capítulo XII, titulado en castellano, por el traductor, "Leyes injustas"; en el original inglés, "Unjust Laws": Finnis 1980/2011: cap. XII.

19 Legarre 1999: 66, nota 5: "un vaso de coca-cola pura es un caso central de coca-cola, mientras que un vaso de coca-cola con un pequeño agregado de agua del grifo también es coca-cola, pero aguada: es una versión aguada de la bebida pero no por ello deja de ser tal, en algún sentido relevante. A tal punto que quien la toma puede engañarse".

20 Finnis 1980/2011: 11. Se habla allí, en el original inglés, de "watered-down version”; y también, como sinónimos, de "undeveloped, primitive, corrupt, deviant [...] instances".

21 De Aquino, Summa Theologiae, I-II, q 95, a2, c.

22 De Aquino, Summa Theologiae, I-II, q 95, a2, c.

23 Véanse Finnis 2012: 111-117 y Legarre 2012: 103-110.

24 Redondo 2018: 19.

25 Finnis 1980/2011: cap. XII.

26 De Aquino, Summa Theologiae, I-II, q 95, a2, c.

27 Legarre 2013: 137-144.

28 Finnis 2012: 111-117.

29 El ejemplo está tomado de Tomás de Aquino, Summa Theologiae, I-II, q 95, a2, c.

30 Esta derivación "intramoral" no debe confundirse con los dos modos de derivación del derecho positivo a partir del derecho natural. Para esta distinción, véase Legarre 2012: 104-107. 


\section{References}

Electronic reference

Santiago Legarre, "Positivismo jurídico "interno" a la luz del derecho natural", Revus [Online], 42 | 2020, Online since 01 September 2020, connection on 23 October 2021. URL: http://journals.openedition.org/revus/6128; DOI: https://doi.org/10.4000/revus.6128

\section{About the author}

\section{Santiago Legarre}

Profesor Titular de Derecho Constitucional, Pontificia Universidad Católica Argentina e Investigador del Consejo Nacional de Investigaciones Científicas y Técnicas (Argentina)

Dirección: Facultad de derecho de la UCA (Bs. As.) - Av. Alicia Moreau de Justo 1300 (C1107AAZ) - C.A.B.A. - Argentina

E-mail: santiagolegarre [at] uca.edu.ar

\section{Copyright}

All rights reserved 